\title{
Rutas y lugares de patrimonio industrial en Europa: consideraciones sobre su aprovechamiento turístico
}

\author{
Carlos J. Pardo Abad \\ Departamento de Geografía de la UNED
}

\begin{abstract}
RESUMEN ABSTRACT
Muchas zonas de Europa se han caracterizado en los dos últimos siglos a través de la actividad industrial. Los edificios industriales son tanto el testimonio del desarrollo económico y social como la expresión de la identidad regional. Conservándolos y haciendo de ellos algo útil para la población se consigue mantener vivo un importante aspecto de la historia europea, creando una base potencial para un nuevo desarrollo económico y regional. EI patrimonio industrial ofrece muchas oportunidades como recurso turístico y

hay muchos ejemplos al respecto en Europa: museos, centros culturales y de

Many areas of Europe have been characterised in recent centuries by industrial activity. Industrial buildings are both the witness of economic and social development and the expression of regional identity. Preserving them and making them available to the population helps to keep this important aspect of European history alive, and creates a potential basis for new economic and regional development. Industrial heritage offers many opportunities as a tourist resource and there are numerous examples in Europe: museums, cultural and interpretation centres have been created in old abandoned factories.
\end{abstract} interpretación se han abierto en viejas fábricas ya abandonadas.

PALABRAS CLAVE: Patrimonio industrial, turismo, rutas de KEYWORDS: turismo industrial. Industrial heritage, tourism, routes of industrial tourism.

\section{PLANTEAMIENTO GENERAL}

La Europa actual no podría entenderse sin tener en cuenta el proceso de desarrollo industrial iniciado en el Reino Unido en la segunda mitad del siglo XVIII y extendido posteriormente por el resto del continente, de forma más inmediata en su 
parte occidental y más tardía en la meridional y oriental. La industrialización transformó y conformó Europa sobre la base de la producción fabril en lo que antes había sido artesanal y manufacturero, en un proceso fundamental sin el cual no podría entenderse no sólo la historia económica sino también social, ambiental y política de nuestro continente en los dos últimos siglos.

Las huellas de este desarrollo están todavía muy presentes: fábricas, maquinaria antigua, paisajes, viviendas obreras, obras de infraestructura de diferente naturaleza (canales, represas, diques), etc. completan de algún modo la memoria de hombres y mujeres aún vivos que con su esfuerzo han contribuido a la historia europea del trabajo y la producción. Son elementos todos ellos de nuestro patrimonio industrial que ayudan a comprender, por más que nos parezcan algunos ya extraños, la cultura material y técnica desde el siglo XVIII.

Es indudable que las interpretaciones más recientes señalan al patrimonio industrial como parte de un patrimonio cultural más amplio. La industria, como manifestación material de las aspiraciones de avance y progreso de la colectividad, ha contribuido innegablemente a la configuración de nuestra identidad común. Su importancia es evidente y su preservación obligada en aquellos casos de mayor significado técnico, social o territorial. Sin embargo, este patrimonio aún no se percibe con la misma trascendencia histórica que otras manifestaciones de nuestro pasado, quizá por la propia consideración temporal que se otorga desde su origen a las instalaciones de tipo fabril. Es más, tienden a relacionarse con los efectos nocivos derivados de la contaminación, ruidos o, incluso, explotación laboral.

Sólo en tiempos muy recientes se ha tomado verdadera conciencia de la dimensión cultural-patrimonial de los restos heredados de la industrialización. Se ha tardado más que en el caso del patrimonio preindustrial (molinos, ferrerías, alfares, ingenios hidráulicos...) por un problema añadido con el que ha tenido que enfrentarse el patrimonio industrial: la rápida obsolescencia física de sus instalaciones y el desfase crecientemente acelerado por la evolución tecnológica, reduciéndose los periodos de uso de sus instalaciones. Mucho material en desuso se ha destruido y no en todos los casos se ha sabido reaprovechar a tiempo tras el abandono.

En la actualidad se ha avanzado bastante en todo aquello relacionado con la protección del patrimonio industrial europeo. Se ha llegado a conseguir una situación casi de reto en la que se aspira a superar los rígidos criterios esteticistas en la valoración de lo patrimonial, recuperándose y reutilizándose con distintos fines (incluidos los turísticos) importantes muestras de un pasado verdaderamente intenso y espléndido de los últimos doscientos años.

Las posibilidades de incorporar nuevas funciones son amplias por las propias características de las construcciones industriales: grandes ventanales, salas diáfanas, estructuras y materiales resistentes, etc. Todo esto juega a favor de la reutilización e interviene como un importante activo que contrarresta los inconvenientes y dificultades que también existen. En alguna ocasión se ha puesto de manifiesto, incluso, el vínculo de la conservación del patrimonio industrial con los nue- 
vos planteamientos de la economía sostenible, en la que tan presente está el concepto de la reutilización ${ }^{1}$.

La introducción de nuevos usos debe de saber afrontar el problema de la gran cantidad de restos heredados, sobre todo en algunas localizaciones, y seleccionar convenientemente aquellos elementos más significativos del pasado industrial con el objetivo de conseguir una protección lo más adecuada posible. En este sentido son ya bastantes los edificios industriales en toda Europa que cuentan con la categoría de monumento y, como consecuencia, con la necesaria protección.

Se ha seguido un criterio riguroso que ha perseguido una selección en la que estén representadas las distintas fases de la industrialización, las tipologías arquitectónicas, los diversos subsectores industriales y los territorios más afectados por la producción fabril. La protección se ha centrado tanto en las instalaciones industriales como en el paisaje, las huellas de la explotación minera o el urbanismo asociado a la industria. Es el caso del valle del Derwent en el Reino Unido, que se extiende a lo largo de más de $20 \mathrm{~km}$ y en el que se han conservado fábricas, poblados obreros, canales, casas de los industriales, líneas férreas..., pudiéndose interpretar no sólo la complejidad de la implantación industrial sino la configuración urbanística de un amplio territorio.

La selección de elementos también ha pretendido insertar o integrar al patrimonio industrial en el conjunto del patrimonio histórico, favoreciendo la investigación de los vestigios industriales y su difusión cultural y educativa. Muchos museos se han abierto a lo largo del continente, en lo que antes eran espacios productivos inundados por el ruido envolvente de las máquinas, con un objetivo primordial que va más allá de la pura conservación: la divulgación didáctica de los restos y procesos industriales.

\section{CONSERVACIÓN Y VALORACIÓN DEL PATRIMONIO INDUSTRIAL EN EUROPA}

Teniendo en cuenta que fue en el Reino Unido donde nació la Revolución Industrial, es lógico que fuera en este país sonde surgiera por primera vez la necesidad de conservar y catalogar a los restos industriales como elementos de carácter patrimonial. Esos restos estuvieron en la base del dominio económico y político inglés durante más de un siglo y medio, con una superioridad tecnológica muy evidente sobre el resto de naciones.

Las primeras manifestaciones en defensa de la conservación de este patrimonio en Gran Bretaña se remontan a los comienzos de la década de 1960, junto

1 Ver a este respecto las actas del Congreso Vasco de Patrimonio Industrial celebrado en Bilbao en Octubre de 2001 con el título de Gestión del Patrimonio Industrial en la Europa del siglo xxI. 
a una serie de investigaciones y estudios en varias universidades del país que sirvieron para crear una nueva disciplina: se denominó Arqueología Industrial. Aparecieron numerosas asociaciones locales que pretendian la salvaguarda de elementos industriales concretos y apareció otra de carácter nacional con el nombre de Association for Industrial Archeology (AIA). El resultado de todas estas iniciativas fue verdaderamente positivo, ya que se ha logrado preservar y proteger un importante número de manifestaciones materiales del pasado industrial británico e incorporarlas a las rutas turísticas del país como un recurso que completa los diversos atractivos de las regiones.

En la década de 1960 se creó un museo en Ironbridge, lugar que pasa por ser la cuna de la industrialización porque fue aquí donde se fundió hierro con carbón mineral por primera vez. La apertura de este centro sirvió de referencia a otros museos industriales que después habrian de crearse en el Reino Unido y en otros países europeos. Buena prueba de la trascendencia del lugar es que en Ironbridge se celebró la primera conferencia internacional sobre patrimonio industrial, cuyo resultado más importante fue la creación de The International Committee for the Conservation of the Industrial Heritage (TICClH).

Después de Ironbridge se celebraron más reuniones en Bochum (Alemania) en el año 1975, Suecia (1978), Lyon (1981), Boston-Lowell (1984), Viena (1987), Bruselas (1990), Madrid (1992), Canadá (1995), Tesalónica (1997), Londres (2000), Moscú (2003) y Japón (2005). En esta última reunión se ha abordado el tema del turismo industrial y su promoción entre el público en general como forma de conservación y buen uso del viejo patrimonio fabril. La conferencia la ha celebrado la TICCIH en colaboración con el International Forum for Industrial Tourism.

Durante todo este periodo, la conservación de los restos industriales se ha extendido desde Gran Bretaña a otros países: primero por el Norte de Europa y otros países industrializados (Estados Unidos, Canadá y Japón); luego por el Sur del continente, es decir, en aquellos países que no habían formado parte del núcleo de la primera Revolución Industrial, aunque puntualmente existieran zonas en las que este proceso se iniciara con bastante prontitud. El Norte de Europa, con un patrimonio artístico menos rico y variado, los restos de la industrialización se han acogido con entusiasmo como parte integrante de su patrimonio cultural ${ }^{2}$.

En cualquier caso, las experiencias de la Europa mediterránea también son interesantes y en la actualidad las reutilizaciones del patrimonio son muy variadas tanto en Francia como en Italia, Portugal, España o Grecia. En una fecha muy temprana (1974) se creó en Francia el Ecomuseo de Le Creusot, convertido desde un principio en referencia obligada para la conservación de un número elevado de restos sobre un amplio territorio. Más hacia el Este, otros países también se han sumado a la recuperación del legado industrial, sobre todo Polonia, Hungria, la Re-

2 Casanelles, E. (2002): "El patrimonio industrial en el contexto internacional», en: Gestión del Patrimonio Industrial en la Europa del s. xxı, Bilbao, Congreso Vasco de Patrimonio Industrial, p. $309-315$. 
pública Checa y Eslovenia. De esta forma, la conservación y reutilización de los edificios industriales para otras funciones ha sido constante e imparable y ha acabado por convertirse en una de las señas comunes de intervención de todo el patrimonio cultural europeo.

En España las iniciativas de protección y conservación son relativamente recientes. Los primeros encuentros para debatir las cuestiones más importantes del patrimonio industrial tuvieron lugar en la década de 1980, como las I Jornadas sobre Protección y Revalorización del Patrimonio Industrial celebradas en Bilbao en 1982. Desde entonces han tenido lugar diferentes reuniones sobre patrimonio industrial y obra pública (Sevilla, 1990), arqueología industrial de Cataluña (L'Hospitalet del Llobregat, 1991), el VII Congreso internacional de la TICCIH (Madrid, 1992), sobre gestión del patrimonio industrial (Bilbao, 2001), etc.

Desde el punto de vista normativo destaca la Ley de Patrimonio Histórico Español, de 25 de Junio de 1985, que da inicio (aunque sin tratamiento específico) a la protección del patrimonio industrial en nuestro país. Esta se amplía a nivel autonómico con una serie de textos, muchas veces heterogéneos y con enfoques distintos. Desde el año 2000 está en marcha el Plan Nacional de Patrimonio Industrial del Instituto del Patrimonio Histórico Español, con un conjunto de 49 intervenciones urgentes en las que se incluye no sólo la maquinaria y los edificios industriales aislados sino también los conjuntos, los paisajes industriales y los entornos socioeconómicos.

Con anterioridad a este plan ya se efectuaron algunas recuperaciones significativas, a veces aisladas y en otras formando amplios sistemas territoriales: es el caso del Museu de la Ciència i de la Tècnica de Catalunya, con sede en Tarrasa y un total de 16 museos dependientes por toda la región. La idea del museo nació en 1976 cuando todavia había muy pocos museos de estas características en Europa. En 1981 se asumió como proyecto oficial y se barajaron varios edificios como sede del museo: finalmente se decidió la adquisición del antiguo "vapor» textil Aymerich, Amat i Jover de Tarrasa, de estilo modernista y magnífica construcción. En Abril de 1984 quedó inaugurado, dándose posteriormente los pasos necesarios para crear una red cohesionada de museos especializados que en la actualidad conforman este sistema original de colecciones y edificios recuperados.

El patrimonio industrial ha acabado por lograr el debido reconocimiento cultural como testimonio del pasado económico, técnico y social de los siglos XVIII, XIX y $x x$. Esto se observa en las acciones emprendidas desde hace ya algún tiempo por la UNESCO, en concreto por su Comité de Patrimonio. Este organismo elabora la Lista del Patrimonio Mundial, siendo 1978 el año en el que incluyó en dicha lista el primer emplazamiento industrial: la mina de sal de Wieliczka en Polonia. Desde esa fecha se han incluido otros lugares más, lo que demuestra el firme propósito de este organismo internacional de preservar debidamente los testimonios de la industrialización y de mantener un criterio amplio y poco restrictivo a la hora de definir lo patrimonial. 
En la Tabla 1 adjunta aparecen algunos de los elementos europeos más importantes declarados Patrimonio de la Humanidad por la UNESCO, aquellos pertenecientes a los siglos XVIII, XIX y XX, junto al país de localización y el año en que fueron inscritos como tales. Son fábricas aisladas, paisajes industriales conservados como hace décadas, líneas férreas, poblados obreros, es decir, formas variadas de un mismo proceso de industrialización en nuestro continente. En esta lista aún no figura ningún conjunto español pero están a la espera de la catalogación los poblados industriales de los ríos Llobregat y Ter en Cataluña. Sí aparecen, por el contrario, aunque sin pertenecer propiamente a los testimonios de la Revolución Industrial de los dos últimos siglos, el acueducto de Segovia y Las Médulas, ambos de época romana.

Tabla 1. Elementos industriales declarados Patrimonio de la Humanidad en Europa: siglos XVIII, XIX y XX

\begin{tabular}{lll}
\hline Elemento & País & Año \\
\hline Ferrocarril de Semmering & Austria & 1998 \\
\hline Elevador hidráulico del Canal del Centro & Bélgica & 1998 \\
\hline Fábrica Verla & Finlandia & 1996 \\
\hline Salina Real de Arc-et-Senans & Francia & 1982 \\
\hline Canal del Midi & Francia & 1996 \\
\hline Planta siderúrgica de Völklingen & Alemania & 1994 \\
\hline Mina Zollverein & Alemania & 2001 \\
\hline Poblado industrial de Crespi d'Adda & Italia & 1995 \\
\hline Estación de bombeo a vapor Wouda & Holanda & 1998 \\
\hline Mina de Sal de Wieliczka & Polonia & 1978 \\
\hline Fábrica metalúrgica de Engelsberg & Suecia & 1993 \\
\hline Área minera de Falun & Suecia & 2001 \\
\hline Estación de radio Varberg & Suecia & 2004 \\
\hline Ironbridge & Reino Unido & 1986 \\
\hline Paisaje industrial de Blaenavon & Reino Unido & 2000 \\
\hline New Lanark & Reino Unido & 2001 \\
\hline Poblado industrial de Saltaire & Reino Unido & 2001 \\
\hline Fábricas del valle del Derwent & Reino Unido & \\
\hline Fuent UnesCo, & & 2001 \\
\hline
\end{tabular}

Fuente: UNESCO, Lista del Patrimonio Mundial. 


\section{Elementos industriales declarados Patrimonio de la Humanidad en Europa: siglos XVIII, XIX, XX}

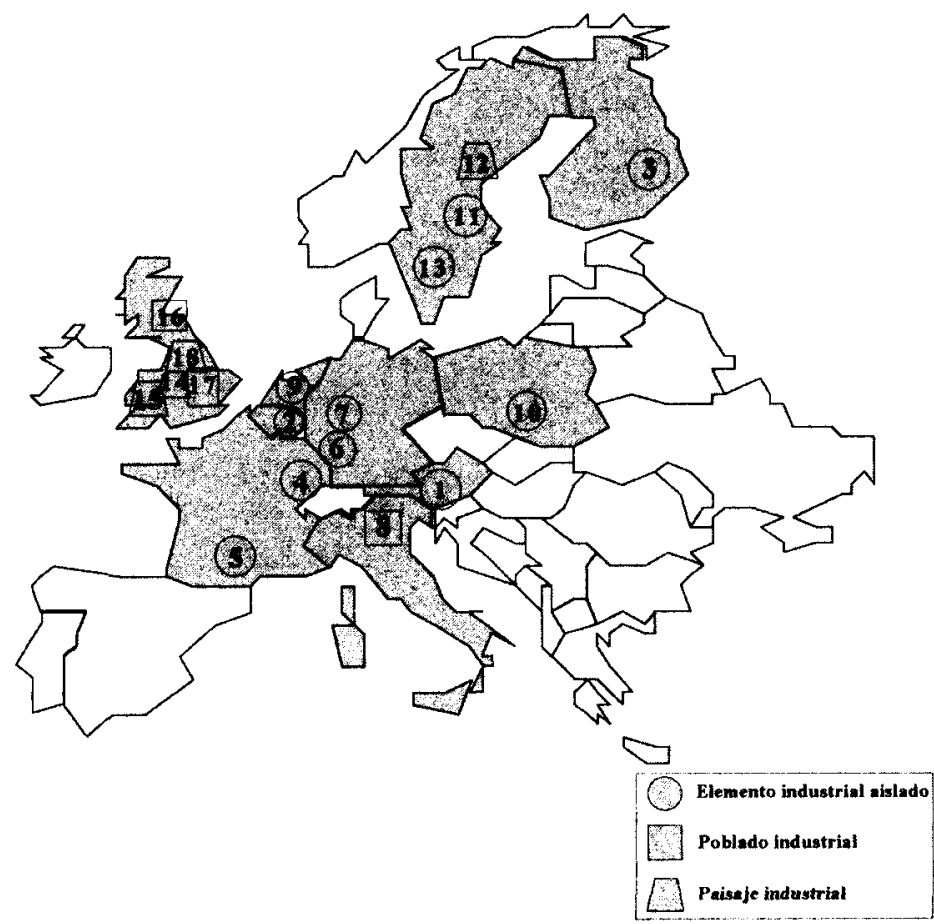

\section{Ferrocarril de Semmering}

2. Elevador hidráulico del Canal del Centro

3. Fábrica Verla

4. Salina Real de Arc-et-Senans

5. Canal del Midi

6. Planta siderúrgica de Völklingen

7. Mina Zollverein

8. Poblado industrial de Crespi d'Adda

9. Estación de bombeo a vapor Wouda
10. Mina de Sal de Wieliczka

11. Fábrica metalúrgica de Engelsberg

12. Area minera de Falun

13. Estación de radio Varberg

14. tronbridge

15. Paisaje industrial de Blaenavon

16. New Lanark

17. Poblado industrial de Saltaire

18. Fábricas del valle del Derwent

\section{VISITANDO LA CUNA DE LA REVOLUCIÓN INDUSTRIAL: EL REINO UNIDO}

Gran Bretaña es el país donde comenzó la Revolución Industrial y también la preocupación por recuperar los restos de la industrialización. La experiencia británica es una de las más interesantes de Europa: muchos testimonios del pasado industrial han sido debidamente recuperados con intervenciones basadas en muchos casos en proyectos de carácter turístico. 
Numerosas ciudades del país cuentan ya entre sus atractivos turísticos las obsoletas fábricas rehabilitadas y reutilizadas. Nosotros nos vamos a centrar aquí, como forma de acotar el amplísimo conjunto de intervenciones, en aquellas que han pasado a formar parte de la lista del Patrimonio Mundial de la UNESCO.

La trascendencia de Ironbridge está fuera de toda duda, ya que pasa por ser la cuna de la Revolución Industrial. El lugar se localiza en el centro de Inglaterra, en el valle del río Severn, en un área en la que abunda el hierro, la arcilla y el carbón mineral. Desde principios del siglo XVIII (1709) se levantó un alto horno en el que se fundió por primera vez el hierro con carbón mineral. En 1779 se construyó el primer puente de hierro fundido del mundo, hecho que brindó la ocasión para cambiar el nombre del emplazamiento de Coalbrookdale a Ironbridge. Además, aprovechando la existencia de una buena arcilla pronto se instalaron también varias fábricas de porcelana y azulejos.

A finales de la década de 1967 (y tras las primeras excavaciones de arqueología industrial del mundo para rescatar el alto horno antes citado) se organizó un museo, luego ampliado con otros nuevos y con visitas a varios sitios de interés histórico. Las visitas superan ya las 800.000 personas anuales y el aprovechamiento turístico del lugar da empleo a más de 2.000 trabajadores locales.

Más al Este de Ironbridge, no lejos de las ciudades de Sheffield y Nottingham, en la región de Derbyshire, el río Derwent concentra un elevado número de fábricas de la primera industrialización en las que se instaló la nueva tecnología inventada por Richard Arkwright para el hilado de algodón. Es la zona en la que surgió por primera vez en el mundo la producción a gran escala en un espacio previamente rural. Además hay que hacer notar que la necesidad de construir numerosos equipamientos y viviendas para los obreros dio origen a las primeras ciudades industriales modernas. El paisaje resultante es de alto interés turístico por la aproximación que ofrece al visitante a la historia y la tecnología de los inicios de la industrialización.

Las invenciones de Arkwright se aplicaron por primera vez en una fábrica construida en 1771 en la localidad de Cromford, luego en otra en 1776; muy pronto los mismos procedimientos técnicos fueron imitados en otros lugares del país y, a pesar de la legislación que impedía entonces la exportación de tecnología, en Alemania y Estados Unidos. Quizá el mejor ejemplo de fábrica del valle del Derwent sea la Masson Mill (1783), en la que se ha abierto el Museo del Trabajo Textil, con una colección de maquinaria histórica original que traslada al turista directamente hasta el siglo xVIII. En la fábrica Belper North Mill se ha creado el Centro de Visitantes del Valle del Derwent, con algunas máquinas textiles dignas de contemplar, como la spinning jenny de Hargreave y la water frame de Arkwright.

Más al Norte de Inglaterra, en la región de West Yorkshire, el turista preocupado por el patrimonio industrial puede visitar Saltaire, ejemplo bien conservado de ciudad industrial de mediados del siglo xIx y cuyo trazado ejerció una influencia decisiva en el desarrollo de las ciudades-jardín. El plano urbano no ha sufrido cambio alguno, se mantiene intacto, y la arquitectura refleja como pocas la estética propia 


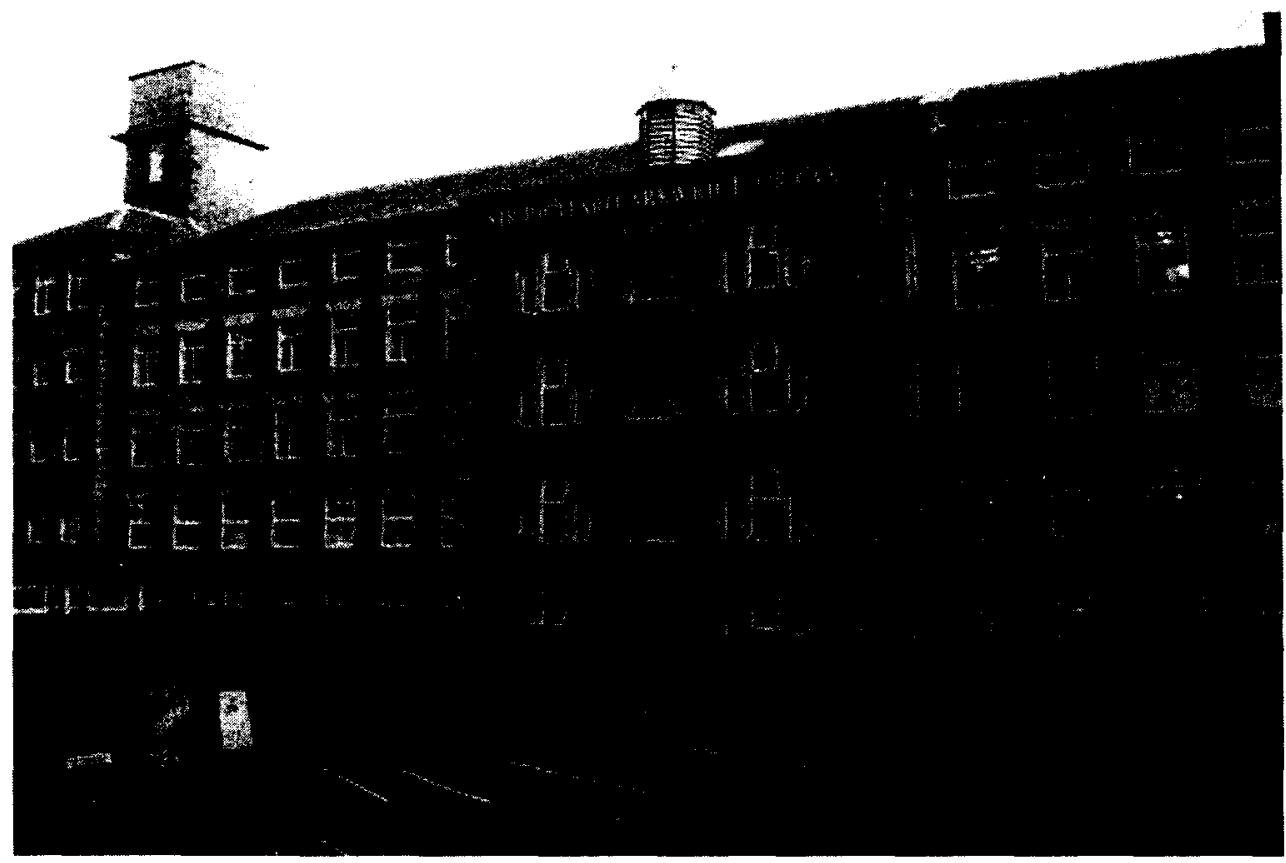

Fábrica del Valle del Derwent. Fuente: Working Textile Museum.

de la llamada época victoriana y el impulso económico aportado por la industria textil. Los edificios constituyen un modelo único de colonia industrial, concebida por Titus Salt como modelo alternativo a las conflictivas fábricas urbanas de las ciudades próximas de Bradford y Leeds. El lugar de mayor interés turístico es la fábrica, conocida como Salts Mill, convertida en un centro cultural y de arte con el nombre de 1853 Gallery.

En Escocia, a unos $40 \mathrm{~km}$. de Glasgow, se encuentra New Lanark, en un paisaje evocador de suaves colinas atravesadas por tranquilos ríos. Este asentamiento industrial se fundó en 1785 y desde un principio se vinculó con un sector clave de la naciente Revolución Industrial: el tejido del algodón. Entre 1800 y 1825 estuvo dirigido el lugar por Robert Owen, reformador social que aspiraba a una sociedad ideal.

En 1968 finalizó la producción industrial y cinco años después se declaró el área como de conservación prioritaria para evitar el deterioro físico de los edificios, la mayoría georgianos y construidos en piedra.

El desarrollo turístico ha sido la pieza clave en la regeneración económica de New Lanark y su comarca. Se ha creado un centro de visitantes y hay varias infraestructuras hoteleras, así como una sala de exposiciones en el viejo almacén del pueblo (original de Robert Owen y base del movimiento cooperativo que implantó en la comunidad) y visitas guiadas que se centran en sus visionarias reformas so- 
ciales y educativas. Anualmente New Lanark atrae a un elevado número de visitantes que buscan conocer el mejor ejemplo conservado de un poblado textil del primer periodo de la industrialización británica, por lo que es evidente su relevancia a nivel internacional ${ }^{3}$.

Al Sur de Gales se encuentra un punto clave de la industrialización del siglo xIx: el paisaje industrial de Blaenavon. Es un paisaje directamente originado por el impacto de la minería del carbón y del hierro: minas de carbón, un primitivo sistema ferroviario, hornos, viviendas obreras y toda la infraestructura social de la comunidad. Los testimonios de este pasado son muy abundantes y adquieren especial protagonismo en la ciudad de Blaenavon, con la mayor parte de los edificios del primer periodo victoriano construidos antes de 1870. Desde el centro de visitas se pueden realizar varios recorridos industriales de carácter turístico, entre los que se incluye la vieja mina Big Pit, en donde se ha creado el Museo de la Mina de Gales.

Las políticas de regeneración urbana han contemplado en todos los casos la conservación y reutilización del patrimonio industrial. La ciudad de Manchester es un excelente referente en este sentido, siendo sus viejas fábricas textiles un elemento característico del paisaje urbano durante más de 200 años. Se ha creado el Parque Castlefield de Patrimonio Urbano: abarca un amplio sector de la ciudad y en él se incluyen los restos del antiguo fuerte romano, el brazo oriental del canal Bridgewater (1760), varios almacenes y la estación de la Liverpool Road Railway. En esta estación se inauguró en 1983 el Museo de la Ciencia e Industria de Manchester. La "pieza" clave del museo es precisamente el edificio de la estación de pasajeros de 1830, la más antigua del mundo.

Complemento de esta parte central de la ciudad es el barrio de Ancoats, cuya visita puede ofrecer al turista la posibilidad de conocer el primer suburbio industrial del mundo, basado en el vapor y sus numerosas fábricas de hilado de finales del siglo XVIII y principios del XIX. El barrio ha solicitado recientemente su catalogación como Patrimonio de la Humanidad, aunque ya ha sido preservada una buena parte del barrio como Área de Conservación. El resto de las ciudades británicas cuentan igualmente con experiencias turísticas interesantes, como la recuperación de los Docklands de Londres y la apertura de varios museos en edificios históricos industriales, como la Tate Modern en una antigua central eléctrica ${ }^{4}$.

\section{EN TORNO AL CONCEPTO DE ECOMUSEO: LA EXPERIENCIA FRANCESA}

El patrimonio industrial goza en Francia de los mismos privilegios que en el Reino Unido y ha sido convenientemente inventariado, lo que ha facilitado su in-

3 Davidson, L. (1998): «Restaurando New Lanark», Ábaco. Revista de Ciencias Sociales, 19, p. 29-34.

4 Ver a este respecto la siguiente comunicación: PARDO ABAD, C. J. (2004): "Las ciudades británicas y la rehabilitación turística y residencial del patrimonio industrial», VI Jornadas Internacionales sobre $P a-$ trimonio Industrial, Universidad de Oviedo-INCUNA. 
vestigación y el debate público en torno a los valores que presenta. Se han trazado algunas rutas industriales relacionadas con el textil o la minería (que completan las turísticas más tradicionales por la costa mediterránea, Bretaña o el valle del Loira) y se han puesto en uso con nuevas funciones muchos testimonios de la vieja industrialización francesa. Como en el Reino Unido, algunas recuperaciones se enmarcan en programas más amplios de regeneración urbana: Lille, Roubaix, Sedán, Lyon, etc. ${ }^{5}$

Lo que más destaca en Francia en relación con nuestro tema es la creación de un nuevo concepto de museo industrial: el ecomuseo. Esta palabra surgió en un congreso celebrado en Francia en 1971 sobre patrimonio industrial; el objetivo principal de un ecomuseo es mantener al visitante en contacto con la información y ofrecerle pautas de interpretación que le permitan interactuar con el medio externo, es decir, trasciende el ámbito de la edificación donde funciona. Además, los ecomuseos son un instrumento muy válido de desarrollo regional ya que, en general, el trabajo es ejercido en colaboración con la población local y las instituciones públicas.

En las ciudades francesas de Le Creusot y Montceau-les-Mines, la actividad industrial disminuyó considerablemente debido a la reconversión de la época de la postguerra. Se incrementó el paro y cerraron muchas minas de carbón y plantas siderúrgicas, con la consecuente migración de población. Esto hizo pensar en la idea de recuperar los espacios industriales abandonados (friches industrielles en francés) y crear un museo que preservara la memoria productiva de esta región del Este de Francia, involucrando a los habitantes en el nuevo proyecto.

El ecomuseo, creado en 1973, constituye una experiencia única y pionera en el mundo sobre recuperación y nuevo uso a gran escala de numerosos edificios en un amplio territorio. Abarca un área urbana bastante amplia de más de 100.000 habitantes y muchos testimonios de industrias ligadas en su día a la extracción carbonífera y la producción siderúrgica. Ya en 1785 se creó una fábrica real de cristales, manufactura que servía para abastecer de cristales a la corte. A principios del siglo XIx la manufactura cerró y el edificio (conocido como Château de la Verrerie) sirvió de residencia a la familia de los Schneider, que supo dar a la zona un impulso industrial sin precedentes en Francia ya desde la primera mitad del siglo XIX. Para la familia Schneider trabajó François Bourdon, inventor del martillo pilón de vapor que dio a la localidad su preeminencia en la industria metalúrgica mundial. Ese pilón es hoy en día el símbolo de toda la ciudad.

La sede del ecomuseo se estableció en el Château ya citado y desde allí se coordina la visita de los dos conjuntos de actividades: el de las industrias metalúrgicas y del transporte en Le Creusot y el de las extractivas del carbón y sus industrias derivadas en Montceau-les-Mines.

5 Dorel-Ferré, G. y Ferriot, D. (2004): “Itinerarios y rutas del patrimonio industrial en Francia», en: AA.VV:: Rutas culturales y turísticas del patrimonio industrial, Gijón, INCUNA, p. 11-23. 
Próximo a este ecomuseo se encuentra la salina de Arc-et-Senans, en la región del Franco Condado. El turista puede realizar la visita como prolongación de la de Le Creusot-Montceau, a unos $120 \mathrm{~km}$. de distancia. La salina constituye uno de los monumentos más célebres del país por la belleza de su construcción. Data del reinado de Luis XV, es decir, algunos años antes de la Revolución Francesa. En esta época el uso de la sal era fundamental para la conservación de los alimentos y la medicina; sobre su venta el Estado imponía un fuerte impuesto, la gabela, que nutría una importante parte de las arcas de Francia.

La Salina Real funcionaba como una colonia integrada por la fábrica y la comunidad que en ella trabajaba. Construida en forma de semicírculo, incluía viviendas y lugares de producción en un total de 11 edificaciones. El plano semicircular era muy próximo al simbolismo elemental de las ciudades ideales radioconcéntricas. El estilo de las edificaciones estaba claramente inspirado en el manierismo del siglo XvI: las columnas con tambores alternativamente cilíndricos y cúbicos se tomaron directamente de Palladio, como se aprecia en el pabellón central del director. El único edificio de estética industrial era uno ya destruido en el que el agua salina se evaporaba de forma natural antes de ser calentada a fuego. La salina, ya obsoleta por la aparición de nuevas técnicas, cerró en 1895 . Comenzó entonces un periodo de abandono y pillaje de sus piedras, hasta que en 1996 concluyeron las obras de su restauración.

Más al Norte del país el turista industrial encuentra en la región de Nord-Pas de Calais dos lugares muy interesantes: el Ecomuseo de Fourmies-Trélon y el Centro Histórico Minero de Lewarde.

Creado el Ecomuseo de Fourmies-Trélon en 1980, es uno de los primeros de Francia y cuenta con una amplia red de sedes por toda el área urbana de las dos localidades. En cada sede asociada se abordan temas concretos y específicos: los más importantes son el Museo del Textil de Fourmies y el Museo del Vidrio de Trélon.

El Museo del Textil está instalado en la antigua fábrica Prouvost-Masurel, construida en 1874 y dedicada a la industria de la lana. Se puede contemplar un buen número de máquinas que marcan la evolución técnica en la fábrica hasta 1978 , año en que cierra definitivamente. Se conserva la cadena completa de fabricación, desde la lana bruta hasta el tejido final.

El Museo del Vidrio se ubica en una fábrica cristalera del siglo xIx en Trélon. Dispone de un excepcional conjunto industrial formado por edificaciones, infraestructuras técnicas y equipamientos de producción. Comenzó su funcionamiento en 1823 y estuvo en un principio dedicada a la producción de botellas, reconvirtiéndose tras la I Guerra Mundial a los frascos de perfumes para las principales firmas francesas. La exposición muestra los procesos de fabricación y la evolución de las técnicas de producción, con vídeos, maquetas y visitas guiadas.

La creación del Centro Histórico Minero de Lewarde surge en la década de 1980 de la mano de las Houillères du Bassin Nord-Pas de Calais, con el objetivo de con- 
servar y aportar a las generaciones futuras el testimonio de más de tres siglos de actividad minera, industrial y social en esta región del Norte de Francia. El Centro agrupa a $7.000 \mathrm{~m}^{2}$ de edificios industriales sobre una superficie de 8 hectáreas. Es el museo minero más grande del pais y ya ha superado la cifra de los 2 millones de visitantes desde su apertura al público en 1984. El Centro Histórico Minero comprende un museo con más de 15.000 objetos expuestos, un archivo con cerca de 500.000 documentos iconográficos y un centro de cultura científica de la energía.

La visita guiada al museo parte de los viejos baños de los mineros y continúa por la lampistería, recorrido en tren minero y varias galerías con recreación de las condiciones de trabajo. El edificio de la máquina de extracción del pozo número 2 alberga la exposición "La Máquina", que presenta los sistemas de extracción del carbón desde su origen hasta el cierre definitivo en esta zona de lo que se conoce como "laguna carbonífera" del Norte de Francia.

\section{ALEMANIA Y LA RECUPERACIÓN DE LAS GRANDES ÁREAS INDUSTRIALES}

Durante los últimos 40 años, el proceso de desindustrialización ha sido muy intenso en algunas regiones de Alemania, sobre todo en las que, como RenaniaWestfalia, iniciaron la Revolución Industrial basando su crecimiento en el carbón, el acero y las grandes fábricas. Tras los cierres proliferaron los paisajes desolados que obligaron a buscar soluciones y nuevas perspectivas de futuro.

Los edificios industriales fueron una auténtica seña de identidad arquitectónica para la región del Rhin y los nuevos usos se han enfrentado a problemas de difícil solución a pesar de las cuantiosas cantidades de dinero empleadas en su regeneración. El gran tamaño de algunas fábricas, su estructura de hierro y acero o los elevados costes han obligado a una selección de las más representativas para la historia industrial de esta parte del occidente alemán. En cualquier caso, la zona se ha convertido en una de las regiones europeas que mejor ha sabido orientar la conservación y la explotación turística de un riquísimo patrimonio industrial, superar la depresión económica y regenerar un paisaje afectado por la ruina y el abandono.

En la región se ha planteado la denominada Ruta del Patrimonio Industrial con el objetivo manifiesto de preservar la cultura industrial de una de las zonas que alcanzó una mayor concentración fabril de toda Europa. La regeneración paisajística y económica se impulsó a través de la creación del Emscher Park en el distrito del Ruhr y la reutilización de un amplio número de establecimientos. El parque se corresponde con la cuenca del río Emscher, afluente del Rhin, formando un corredor de unos $800 \mathrm{~km}^{2}$ entre las ciudades de Duisburg y Bergkamen.

Los itinerarios propuestos unen entre sí los diferentes proyectos de recuperación y dan estructura al parque. Los lugares y puntos de interés para el turismo industrial son muy abundantes y todos ellos dan a conocer al gran público los testi- 
monios de la industrialización renana. En la ruta hay varios museos, enclaves panorámicos y fábricas de gran tamaño, además de suficiente información específica y cartográfica.

Algunos ejemplos visitables dentro de la ruta son las minas de carbón de Zollverein, Maximilian y Zollern, el gasómetro de Oberhaussen, de 117 metros de altura y convertido en una de las más extraordinarias salas de exposiciones de Europa, los canales del Rhin-Herne y Wessel-Datteln, elevadores de barcos, poblados obreros de Eisenheim, Teutoburgia, Friedriech-Heinrich, etc. Un total de ocho museos se han abierto en la última década para mostrar diferentes aspectos relacionados con la industrialización de los últimos 150 años, logrando convertir a la zona en un importante foco de atracción turística dentro del país.

La mina Zollverein constituye un punto central de todo el entramado industrial de Renania-Westfalia y comprende un conjunto de instalaciones históricas para la extracción del carbón con un alto valor arquitectónico. Es una prueba material excepcional del despegue y declive de esta actividad y uno de los mejores testimonios de un periodo crucial en el desarrollo de las industrias pesadas tradicionales en Europa.

La mina Zollern fue construida en 1898. La extraordinaria arquitectura de la mina y la moderna tecnología empleada desde un principio nos indican la supremacia de la compañia minera dentro del sector en aquella época. La arquitectura puede llegar a ser, incluso, extravagante y los edificios documentan la transición del historicismo (dominante en la parte frontal del complejo) al art nouveau (que se puede observar en la sala de máquinas). El conjunto se ha restaurado por completo y se muestran exposiciones y recorridos en los que se explica el trabajo y los peligros inherentes a la extracción del mineral.

El elevador de Henrichenburg, junto al canal Dortmund-Ems, es otro atractivo turístico en la zona. Inaugurado por el emperador Guillermo II en 1899, su construcción despertó desde un principio un gran interés y puede decirse que se convirtió pronto en un foco de visitas. La gente quería echar un vistazo a la tecnología que permitía elevar barcos de 600 a 800 toneladas para salvar un desnivel de unos 14 metros de altura. El elevador estuvo operativo hasta 1970, aunque desde 1962 fue reemplazado por otro más moderno. Se puede hoy visitar todo el complejo y comprobar el mundo de la tecnología y el vapor en él empleado. También se puede pasear en un barco-museo y observar desde otro punto de vista el mecanismo del elevador.

Otras grandes plantas industriales han sido también recuperadas para la actividad turística en otras partes de Alemania: es el caso de la siderurgia Völklingen en la región del Sarre, muy cerca de la frontera francesa. Esta planta siderúrgica se creó en el año 1873, convirtiéndose muy pronto en el primer centro industrial de perfiles metálicos de todo el país. A finales de la I Guerra Mundial, con seis altos hornos ya levantados, la fábrica se mostraba en líneas generales tal y como se puede ver en la actualidad. Los años de auge fueron en torno a la II Guerra Mun- 
dial y la empresa se dedicó a la fabricación de armamento pesado para el conflicto. La derrota nazi provocó graves problemas económicos a la industria, pero fueron superados en la década de 1950. Los humos, las chimeneas y los altos hornos siguieron siendo elementos principales del paisaje hasta 1986, año en que se produjo el cierre definitivo del emporio.

En el conjunto, de dimensiones considerables, se conservan y visitan los siguientes elementos: 6 altos hornos (1916-1976); 10 estufas (1885-1976); sistema de transporte para la carga de los altos hornos (1911-1918); planta de purificación y tratamiento de gas (1912-1925); depósitos de carbón (1898-1934); 4 baterías de coque (1934-1976); planta de preparación de mineral (1911-1918); edificio que alberga las máquinas soplantes (1900-1938); 7 motores (1905-1914); 3 máquinas de vapor y generadores de energía; planta moderna de laminado (1976); casa de bombas con dos motores de gas (1910); talleres de mantenimiento (1898-1918); y un bloque de oficinas (1912).

Las distintas áreas se han ido poniendo a punto para permitir el recorrido por las instalaciones. El criterio seguido para su catalogación como Patrimonio de la Humanidad en 1994 por la UNESCO fue que constituye un monumento único de la historia técnica e industrial del siglo xIX y de principios del $x x$. Representa un ejemplo extraordinario de planta siderúrgica íntegramente conservada que es capaz de mostrar en su totalidad el proceso de producción. En la visita se muestra la evolución técnica y las innovaciones que han marcado la historia de la siderurgia en los dos últimos siglos.

\section{TURISMO Y PATRIMONIO INDUSTRIAL EN LOS PAISSES NÓRDICOS: SUECIA Y FINLANDIA}

Como en otros muchos lugares de Europa, el cierre de las viejas fábricas, talleres y minas ha sido muy intenso en la fría Europa del Norte. Muy especializada esta zona en algunas ramas industriales básicas (siderurgia, papel, textil...), el proceso de industrialización se inició pronto ante el impulso emprendedor de sus habitantes y la abundancia de hierro, madera y agua. La transformación ocasionada por la industria fue intensa en algunas áreas, cambiando el paisaje y reforzando, incluso, el sentido de identidad de la población.

Frente a otros países industriales, en Suecia y Finlandia las fábricas viejas no han sido tantas veces sustituidas por otras nuevas, se han mantenido a lo largo del tiempo por la existencia de espacio suficiente (que no obliga a reutilizar la misma pieza de terreno) y la ausencia de enfrentamientos bélicos desde principios del siglo XIX. Los testimonios del pasado industrial, por tanto, se han conservado $y$ además empezaron a ser vistos desde muy pronto como monumentos históricos.

La selección de entornos y edificios ha sido constante y siempre se ha contado como requisito imprescindible que los lugares fueran adecuados para la re- 
cepción de visitantes. Se considera que la preservación y puesta en valor del patrimonio industrial colabora en el mantenimiento de las señas de identidad de los territorios y sus habitantes y explica las claves de formación de los paisajes de numerosas zonas.

Los sitios industriales están perfectamente señalados en las carreteras principales, se han instalado abundantes paneles de información, se ofrece a los turistas suficiente documentación y en algún caso se añaden, incluso, dramatizaciones de luz y sonido y la colaboración de trabajadores culturales, de forma que se cuenta con todo aquello que hace al visitante más llamativo y atractivo el recorrido por los lugares de patrimonio industrial.

Bergslagen fue la primera región de Suecia donde se desarrolló la industria y se localiza al Sureste del pais, en torno al lago Mälaren. Abunda el hierro, el agua y los extensos bosques, tres requisitos imprescindibles que hicieron posible la Revolución Industrial en el país y convertir a esta región en la base de la Suecia moderna. En el año 1986 se creó el Ecomuseo de Bergslagen bajo la influencia de las personas que previamente crearon en Francia el de Le Creusot-Montceau, que ya hemos tenido oportunidad de comentar. Convertido el paisaje y su patrimonio industrial en las «piezas" claves, los objetivos principales del ecomuseo son interpretar de forma viva la historia de Bergslagen, proporcionar un perfil cultural a este turismo y proteger entornos y edificios en sus lugares de origen. El ecomuseo cuenta con un total de 49 enclaves visitables, desde minas a altos hornos y fundiciones, casas de trabajadores, canales, ferrocarriles, centrales de energía, etc. Uno de esos enclaves es la fábrica metalúrgica de Engelsberg, declarada Patrimonio de la Humanidad por la UNESCO en 1993.

Esta fábrica fue construida en el año 1681 y se convirtió en una de las más modernas instalaciones metalúrgicas de Europa y del mundo entre 1700 y 1800 . El sitio comprende oficinas, alojamientos de trabajadores, una mansión y diferentes construcciones industriales. Conserva la mayor parte de los equipos técnicos de la época y se mantiene tal cual tras la última remodelación de 1870. Las actividades cesaron definitivamente en 1919, comenzándose la restauración de las construcciones en la década de 1970.

Hoy en día el Ecomuseo de Bergslagen constituye uno de los focos turísticos más importantes de Suecia. La proliferación de recursos naturales (lagos, bosques y ríos) y la proximidad a Estocolmo, Uppsala y Västeras, favorecen las visitas a la zona, que se cifran en torno al medio millón al año; en su mayoría son suecos pero también proceden de Noruega, Dinamarca, Finlandia y el Norte de Alemania. Esto significa, como sucede en otros lugares de Europa, la internacionalización creciente del turismo industrial en el continente.

En Finlandia, la industrialización está intimamente ligada a algunas de sus principales ciudades. Es el caso de Tampere, situada a unos $130 \mathrm{~km}$. al Norte de Helsinki. Tampere constituye la primera ciudad industrial de Finlandia y una de las más importantes de los países nórdicos. No sólo por la historia de su industrialización 
sino también por el desarrollo de una excelente tecnología y una arquitectura de indudables valores estéticos, se han establecido varias rutas turísticas de patrimonio industrial que recorren los hitos más significativos de la ciudad y transportan al viajero a los inicios mismos de su desarrollo industrial.

Una de estas fábricas es la textil algodonera Finlayson. Fundada en 1820 por el escocés James Finlayson, fue por entonces el mayor establecimiento industrial del país. Como en Inglaterra, el algodón centró la primera industrialización textil a gran escala, cuya producción se exportaba sobre todo a la vecina Rusia. La fábrica aprovechó un emplazamiento industrial ideal por la abundancia de agua: los rápidos Tammerkoski, justo en el centro de la ciudad.

La industria es un auténtico monumento industrial de la historia de Finlandia. La parte central, el Kuusvooninkinen de 6 plantas, está protegido y su restauración ha sido supervisada por la Comisión de Edificios Históricos. En la actualidad, el sonido de las máquinas ha cesado pero los edificios están todavía en plena actividad: hay varias oficinas, estudios de arte, espacios para exposiciones temporales y equipamientos deportivos. Las visitas incluyen la fábrica, la colosal máquina de vapor destinada en su día a la producción de electricidad para la industria y todo el área industrial.

En las proximidades se encuentra la vieja fábrica Oy Tampella $A B$, fundada en 1861 para la producción metalúrgica de turbinas, barcos y locomotoras, lo que supuso la ampliación del panorama industrial finlandés más allá de las industrias de

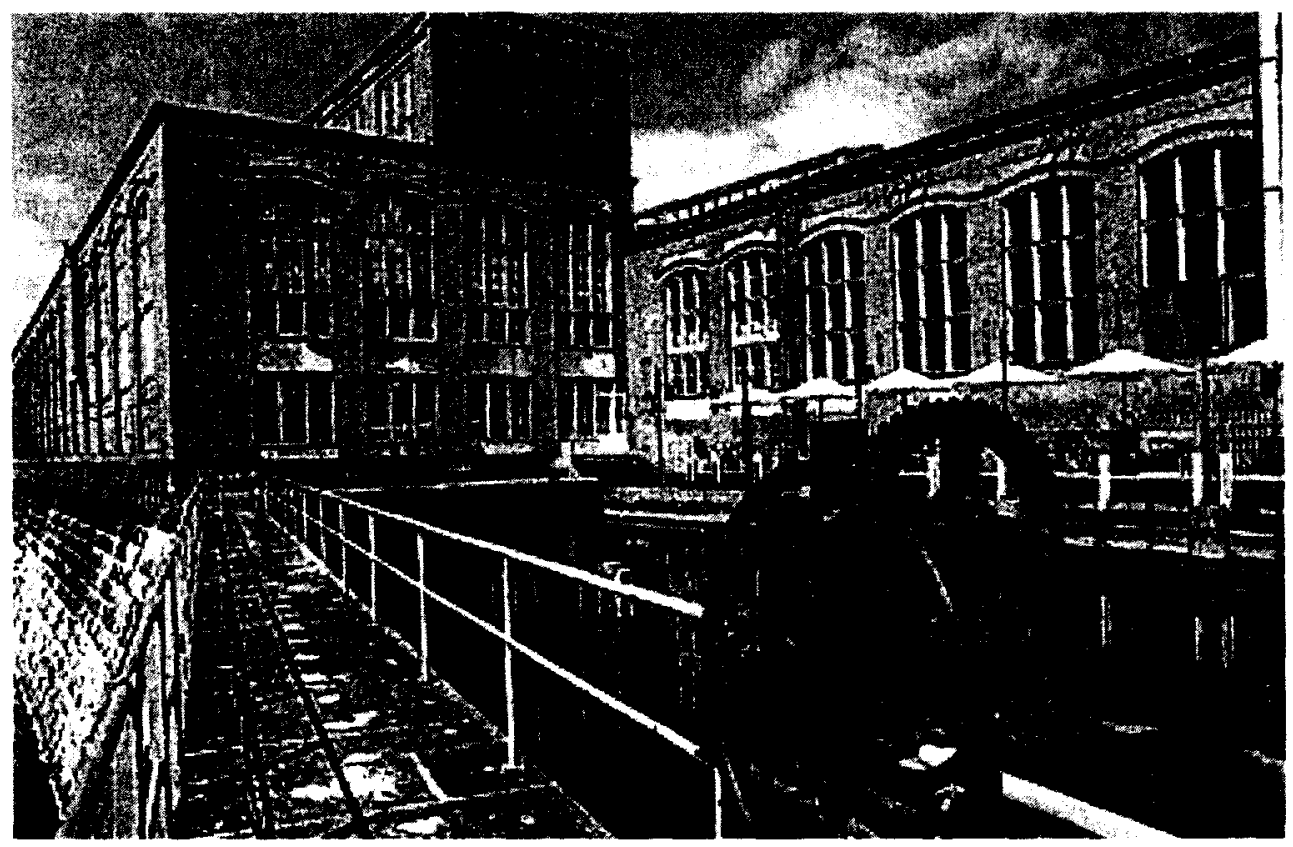

Museo Vapriikki. Fuente: European Textile Network. 
madera, papel y cartón. Durante la II Guerra Mundial el centro manufacturó armas y municiones y tras el conflicto bélico se especializó en las máquinas de producción de papel y tratamiento de la madera. En uno de sus edificios se ha instalado el Museo Vapriikki, en donde se ofrece una buena perspectiva histórica del asentamiento industrial en torno a los rápidos Tammerkoski durante más de un siglo.

El mejor exponente de todo el patrimonio industrial finlandés lo representa la fábrica Verla, a unos $160 \mathrm{~km}$. al NE de Helsinki en el valle del río Kymi. El idílico poblado y la propia fábrica de papel son un ejemplo único de la industria papelera del siglo xix en el Norte de Europa. Su fundación data de 1872, momento en el que la región empezaba a desarrollarse como el centro de la industria maderera y papelera finlandesa. Con varios incendios y reconstrucciones, la industria estuvo en funcionamiento hasta 1964 después de casi un siglo de existencia.

En 1972 se abrió al público el primer museo industrial de Finlandia con el nombre de Verla tehdasmuseo. Se puede visitar todo el conjunto y dentro de la fábrica se muestran las diferentes actividades desarrolladas desde su fundación, así como las distintas tareas para convertir la madera en papel. En 1996 obtuvo la categoria de Patrimonio de la Humanidad.

\section{ITALIA Y EL PATRIMONIO HISTÓRICO-INDUSTRIAL}

Hablar del patrimonio histórico-industrial en Italia exige algunas consideraciones previas. En primer lugar, la industrialización italiana se inició con cierto retraso respecto a la registrada en otras regiones del centro y Oeste de Europa, por lo que los testimonios son algo más recientes; en segundo lugar, en algunas zonas del Norte del país el desarrollo de la Revolución Industrial fue relativamente intenso y anterior al de la mayoría de las regiones mediterráneas europeas; y en tercer lugar, la conservación y valorización de este aparato industrial sólo se ha dado en parte y en fechas recientes. En cualquier caso, la musealización y el aprovechamiento turístico de este recurso cuenta con buenos ejemplos dignos de ser comentados.

En la región de la Toscana se abrió al público en el año 2000 el Museo Minero Abbadia San Salvatore y aprovecha las instalaciones para la producción de mercurio, que comenzó en 1897 y concluyó en 1976. El modelo museístico se basa en la exposición de la tecnología minera para extraer mercurio a partir del cinabrio. Es un proyecto de parque-museo de 8 hectáreas que abarca las zonas de extracción y las instalaciones metalúrgicas para la obtención del mercurio. Es decir, el objetivo es la reconstrucción del proceso productivo y las evoluciones recientes de las técnicas metalúrgicas, mostrando los equipos y las instalaciones en su lugar de uso.

En este museo se han establecido varios recorridos:

1. Recorrido por la excavación en las zonas de extracción del mineral, mediante un pequeño tren que usa los rieles por los que circulaban las carretillas con el mineral. 
2. Recorrido metalúrgico centrado en la obtención del mercurio a partir del cinabrio, con diferentes instalaciones: secadores, hornos, condensadores y máquinas de embotellado.

3. Recorrido a través de las diferentes tecnologías aplicadas durante el periodo de explotación.

También en la Toscana, complementando el rico patrimonio histórico-artístico de esta región del centro de Italia, se encuentra el Parque Arqueo-Minero de San Silvestro. El museo se inauguró en 1996 y es el primero de estas características que se abrió en el país. Representa la musealización de un rico legado minero que se remonta al siglo VII a.C. en el periodo etrusco-romano, continúa en la Edad Media y el Renacimiento y se prolonga, con varias interrupciones, hasta los siglos XIX y xx. Las concesiones mineras a la sociedad inglesa Etruscan Copper Estate Mines en la segunda mitad del ochocientos dejaron los monumentos más interesantes de arqueología industrial: varios restos de lavadoras, de hornos fundidores y hornos de cocción y reducción. Las visitas se incrementan año tras año y hoy rondan las 35.000 anuales, procedentes en su mayoría de los turistas heliotrópicos del cercano litoral tirrénico.

Más al Norte, en la región de Lombardía y próximo a la localidad de Capriate San Gervasio, se encuentra el monumento más interesante de todo el patrimonio industrial italiano: el complejo textil de Crespi d'Adda. El complejo comenzó con el establecimiento, en la orilla del río Adda, de una comunidad ideal para los empleados y constituye hoy el ejemplo más significativo del fenómeno de las colonias industriales en Italia. Se conserva perfectamente en su aspecto urbanístico y arquitectónico y constituye un modelo auténtico de ciudad ideal, casi un microcosmos autónomo dominado por la fábrica y también por los ideales de orden y armonia.

La fábrica y la colonia fueron construidas a finales del siglo XIX (1878) por el industrial algodonero Cristóforo Benigno Crespi y representa el inicio de la industrialización a gran escala en Italia. Era el tiempo de los grandes industriales filántropos que se preocupaban por satisfacer las necesidades de sus obreros, pero también de los empresarios interesados en instalar sus fábricas lejos de los convulsos y revolucionarios centros urbanos. Para cada empleado se daba una casa con jardín y los servicios indispensables: iglesia, escuela, hospital, teatro, baños públicos... ${ }^{6}$. La mayoria de las casas todavía están habitadas por los descendientes de los primeros trabajadores y la fábrica continúa funcionando en el mismo sector textil.

Como ya hemos comentado anteriormente, la urbanística del complejo es extraordinaria: la fábrica se sitúa a lo largo del río, cerca de la mansión de los Crespi; en paralelo a la fábrica se alinean las calles y casas de los obreros, de inspira-

${ }^{6}$ Este mismo modelo se puede encontrar en España en una de las mayores concentraciones de colonias fabriles del mundo en los ríos Llobregat y Ter en Cataluña, propuesto precisamente desde España para su catalogación como Patrimonio de la Humanidad por la UNESCO desde hace ya algunos años. 


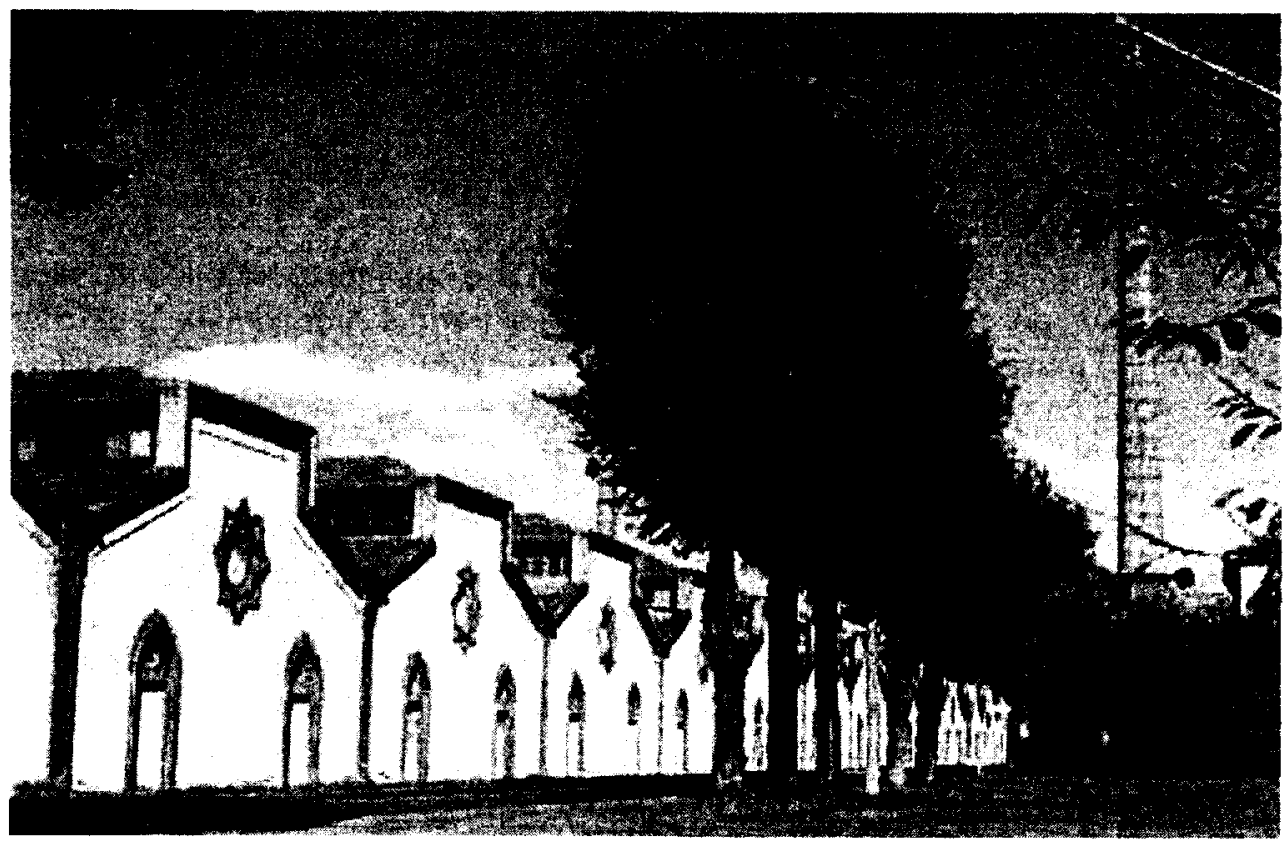

Colonia industrial Crespi d'Adda. Fuente: Associazione Culturale NEMA.

ción inglesa. Los cuadros dirigentes ocupaban casas aisladas y las altas chimeneas acentúan las perspectivas y la importancia de la industria dentro de la colonia; frente a la fábrica se encuentran la iglesia y la escuela. Las construcciones mezclan distintos estilos pero predominan los neomedievales, tan del gusto de la época en toda Europa.

En la región de Piamonte se ha establecido desde hace ya algún tiempo la llamada Ruta de la Lana entre las ciudades de Biella y Borgosesia a través de un recorrido de unos $50 \mathrm{~km}$., con numerosos lugares industriales inutilizados pero testimonio de un rico pasado textil. Además se puede observar todo un sistema territorial de carácter fabril integrado por canales de derivación, centrales eléctricas, poblados obreros, escuelas, hospitales, etc.

El itinerario comienza en el lanificio Alfredo Pria en Biella, fundado en 1824 sin grandes valores arquitectónicos y con un desarrollo en altura al más puro estilo manchesteriano. Centra un área en la que se ubica también el imponente complejo Agostinetti e Ferrua, reconstruido en 1876 tras un incendio.

En la localidad de Miagliano se ubica la fábrica textil algodonera Poma, fundada en 1863, y el poblado obrero correspondiente, cuya construcción data de 1870 y constituye el mejor ejemplo de toda la región. En varios centros dispersos pero próximos, la empresa llegó a emplear a más de 4.000 trabajadores. Otros edificios industriales característicos son las fábricas Carlo Barbera y Giuseppe Botto. 
La más simbólica de toda la ruta, y lugar de especial atracción turística, es la llamada Fabbrica della Ruota, en donde se encuentra desde 1984 el Centro de Documentación de la Industria Textil. Construido el edificio en 1878, ocupa una parcela de más de $2.500 \mathrm{~m}^{2}$ y estuvo en actividad hasta finales de la década de 1960. Se conserva intacto el sistema de transmisión de la energía mediante una gran rueda (ruota en italiano) que, colocada en el extremo exterior del edificio, recogía la energía producida en una turbina localizada a más de 80 metros de distancia mediante un cable de acero. La rueda movía un eje horizontal y éste, a su vez, un sistema de correas verticales que transmitían la fuerza a las otras plantas del edificio. Este sistema es el único caso conocido en Italia.

\section{OTRAS EXPERIENCIAS EUROPEAS}

En el resto del continente las recuperaciones también han sido importantes. Completan un panorama bastante amplio en torno a los nuevos usos turísticos del patrimonio industrial. Lo que hace algunas décadas hubiese resultado tan sólo una utopia hoy constituye una realidad que nace de un interés general por salvaguardar la herencia de la industrialización europea.

En Bélgica destaca la recuperación de numerosas explotaciones hulleras, como las de Argenteau, Bois-du-Luc y Grand-Hornu, las tres en Valonia, con sendos centros turísticos de interpretación y conservación de máquinas y herramientas. También destaca la actuación efectuada en el Canal del Centro, con cuatro ascensores hidráulicos de finales del siglo $\mathrm{XIX}$ y principios del XX para salvar los desniveles topográficos a los barcos. Los ascensores y las salas de máquinas reciben aproximadamente 80.000 visitantes al año.

En Holanda existen varios ejemplos dignos de tener en cuenta. La ciudad de Tilburg constituía una auténtica ciudad textil con numerosas factorías de indudable valor patrimonial. El Museo Holandés del Textil está ubicado en una de ellas: la Mommers and Company. El complejo, que data del siglo xIx y ahora está protegido como monumento nacional, fue restaurado en 1986 para convertirlo en museo.

Sin embargo, la pieza clave del patrimonio industrial holandés es la estación de bombeo a vapor Wouda, cerca de la localidad frisona de Lemmer. Data de la década de 1920, es uno de los mejores conjuntos conservados de máquinas de vapor del mundo y en la actualidad aún funciona como sistema auxiliar de la moderna estación de bombeo.

En Polonia destaca la mina de sal de Wieliczka, cerca de Cracovia. Es el único lugar del mundo donde la actividad minera ha continuado sin interrupción desde la Edad Media. Fue el primer elemento industrial declarado en 1978 como Patrimonio de la Humanidad por la UNESCO. La situación próxima a Cracovia favoreció desde muy temprano el desarrollo de las visitas turísticas. A comienzos del siglo xIX se habilitaron ya varias cámaras históricas del primer nivel. La ruta se 
fue ampliando con nuevas cámaras en los niveles 2 y 3 y desde principios del siglo xx existían ya campañas turísticas organizadas para mostrar el interior de la mina. Las visitas quedaron interrumpidas durante la ocupación nazi. El turismo se reanudó a partir de 1945: si en ese año los visitantes fueron 10.000, en 1955 ascendieron a 200.000 y a mediados de la década de 1970 se superaron los 750.000 anuales. Actualmente, la mina (con más de 800.000 turistas al año) se ha convertido en uno de los mayores atractivos turísticos de toda Polonia.

Austria engrosó la lista del Patrimonio de la Humanidad de tipo industrial con el ferrocarril de Semmering, catalogado como tal en 1998 por ser el primer ferrocarril de montaña trazado en el mundo y el prototipo de línea férrea basada en la construcción de numerosos túneles y viaductos. Su trazado fue diseñado por Carl Ritter y persiguió la mejor contemplación estética posible del paisaje alpino. La línea, que parte de Gloggnitz, pasa por Semmering y llega a Mürzzuschlag, fue construida entre 1848 y 1854 e inaugurada por el emperador Francisco José I. Se planificó para unir Viena con Trieste (único puerto marítimo del Imperio Austro-Húngaro, hoy italiano), atravesando los Alpes por el paso de Semmering a una altura máxima de 898 metros sobre el nivel del mar. Hasta 1860 este fue el punto más alto alcanzado por los ferrocarriles públicos en todo el mundo. Las edificaciones levantadas a lo largo de la ruta (hoy en día utilizadas como segundas residencias en su mayor parte) presentan un carácter arquitectónico homogéneo, por lo que se puede afirmar que la línea representa un conjunto integral hecho bajo una misma percepción estética y técnica que refuerza el carácter turístico de este ferrocarril.

En Portugal destacamos, por el carácter patrimonial de las edificaciones y por la recuperación con fines turísticos, la Fábrica de Chapelaria de San Joao de Madeira (denominada en la localidad como Fábrica Nova porque antes existían otras más dedicadas a la misma producción de sombreros), la fábrica de pólvora de Barcarena, la Real Fábrica de Panos de Covilha (que data del siglo XVIII al amparo de la política de fomento industrial del Marqués de Pombal), la fábrica de cerámica Jerónimo Pereira Campos de Aveiro y el Ecomuseo de Seixal.

En España, el patrimonio industrial es amplio pero hasta la fecha insuficientemente atendido. Son numerosos los ejemplos que hubiesen merecido ya la recuperación y puesta en valor. En Cataluña se da la más enriquecedora experiencia de todo el país, con el sistema territorial del Museu de la Ciència i la Tècnica de Catalunya. La sede se encuentra en un impresionante edificio industrial de tipo modernista en Tarrasa, con sedes asociadas por toda la región en lugares históricos de la industrialización catalana. Cerca de Barcelona, las colonias industriales del Llobregat y del Ter, en la misma capital la fábrica Casarramona y varios centros culturales ocupando viejas fábricas (como el Vapor Vell, por ejemplo).

Fuera de Cataluña el panorama es diferente. Todavía queda mucho trabajo por hacer para recuperar un patrimonio de "segundo orden" frente a la masiva presencia del histórico-artístico por todo el país: aserradero mecánico de Valsaín, Real Fábrica de la Moneda de Segovia, Canal de Castilla y sus numerosas harineras co- 


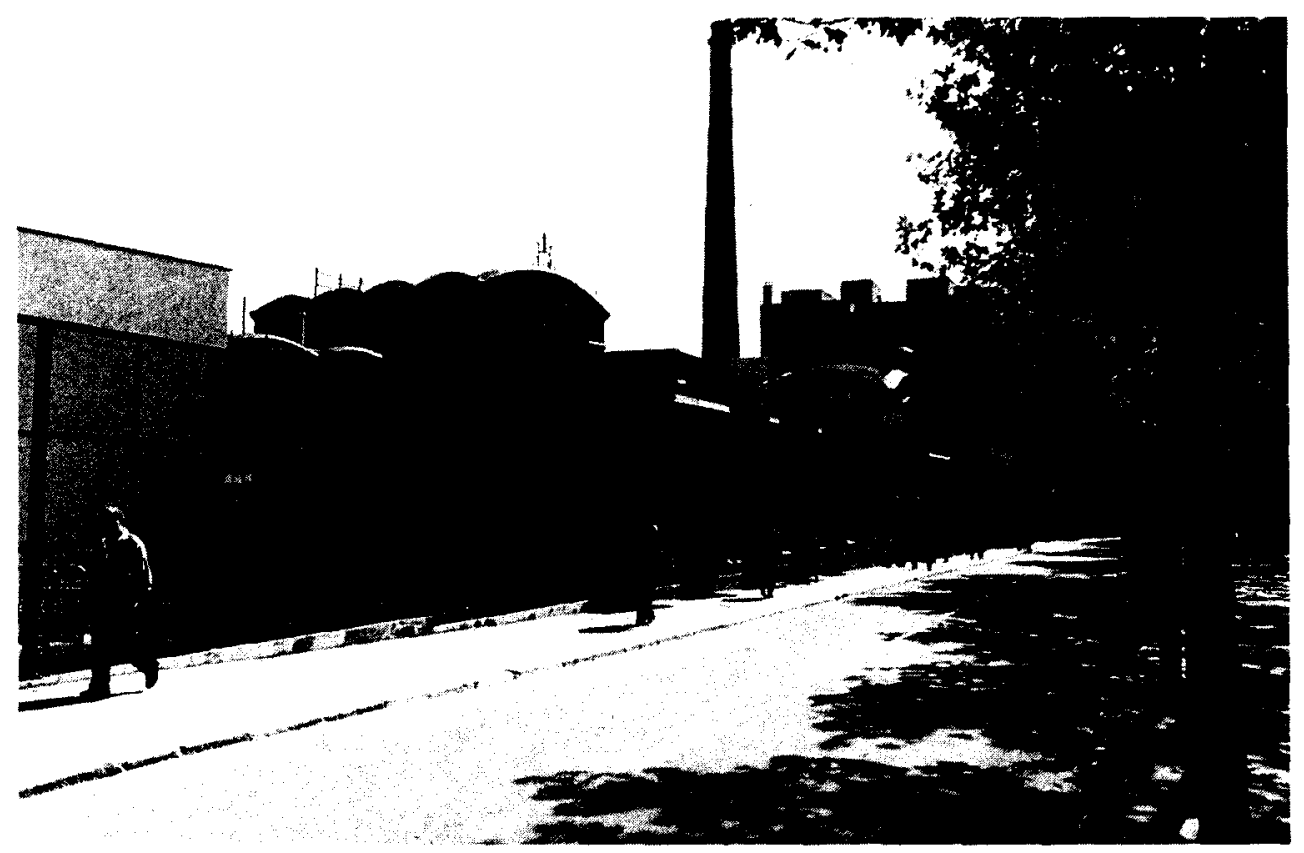

Museu de la Ciència i Tècnica de Catalunya.

lindantes, minas de Riotinto, azucareras de la Costa Tropical en la provincia de Granada, altos hornos de Marbella, fábricas de cerámica repartidas por doquier, ferrerías, molinos... La puesta en marcha en 2000 del Plan Nacional de Patrimonio Industrial representa una inflexión significativa en el que se apuesta por la recuperación y la coordinación entre los organismos estatales y autonómicos. Se han seleccionado en un principio un total de 49 bienes prioritarios y en ellos se ha empezado a intervenir de forma inmediata por su valor testimonial, histórico, arquitectónico, estado de conservación, etc. El turismo industrial podrá cobrar, así, un protagonismo hasta ahora sólo presente en Cataluña, donde se han establecido varias rutas comarcales y temáticas verdaderamente interesantes.

\section{LA RUTA ERIH DE PATRIMONIO INDUSTRIAL EUROPEO}

La Ruta Europea de Patrimonio Industrial, conocida con las siglas inglesas de ERIH, es una red que enlaza una serie de hitos históricos importantes para potenciar las antiguas regiones industriales y el turismo industrial. Surge como idea en el año 1999 y la primera fase se prolonga hasta 2001, periodo en el cual se asocian a la red varias regiones europeas, entre otras el Sarre y Renania del NorteWestfalia en Alemania. Esto se realiza al amparo de la iniciativa comunitaria INTERREG II C. La creación concreta de la ruta ERIH tiene lugar en 2002 con la participación de las regiones alemanas antes citadas y otras de Gran Bretaña y Ho- 


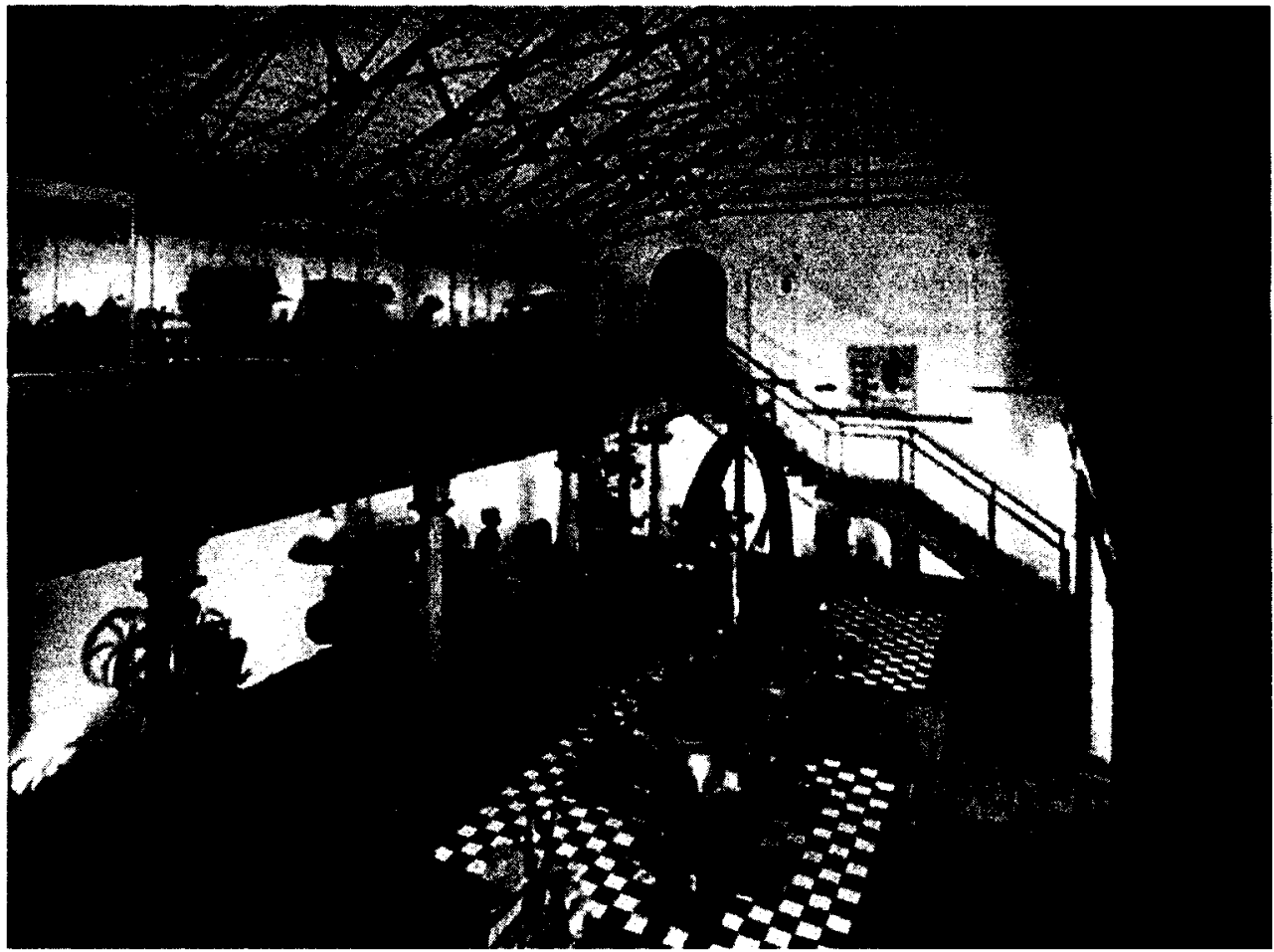

Interior musealizado de una vieja estación de bombeo. Fuente: British Engineerium Museum.

landa. Es el núcleo originario de una gran ruta de patrimonio industrial que enlazará con el tiempo aquellos puntos clave de la actividad industrial en nuestro continente, reconociendo sus características intrínsecas como base para potenciar el turismo industrial. Se trata, en definitiva, de promover la integración europea a través del patrimonio industrial.

El principal organizador de la ruta ha sido el gobierno de Renania del NorteWestfalia, en cuya región ya se creó hace algunos años una ruta de patrimonio industrial con notable éxito turístico y de recuperación de viejas áreas y estructuras fabriles.

La red se ha constituido a través de la participación de los lugares europeos más importantes y atractivos, denominados anchor points o puntos de referencia. Estos puntos quedan unidos por la idea de la trascendencia de su paisaje industrial, así como las regiones o zonas que se agreguen en el futuro. Esos anchor points representan el corazón del patrimonio industrial europeo, por lo que deben dotarse de la necesaria infraestructura turística para un mejor conocimiento e interpretación de dichos lugares. De esta forma está previsto crear en Europa un amplio mercado turístico de tipo industrial que colabore en la presenvación y puesta en uso de los principales testimonios de la industrialización europea de los dos últimos siglos. 
El marketing de la ruta ERIH debe ofrecer de forma adecuada los sitios a visitar, informar a los visitantes sobre la red y cooperar íntimamente con las organizaciones turísticas regionales, nacionales e internacionales. Podemos decir que el éxito de los anchor points está precisamente en la colaboración que se establezca con los organismos turísticos locales. La fortaleza de la ruta quedará garantizada a través de la fortaleza de sus distintos elementos, de su desarrollo y de la correcta promoción, organización y financiación de sus proyectos concretos.

En los organizadores de la ruta ERIH se insiste en la idea del reciclaje de las arquitecturas industriales y los valores medioambientales que entraña su recuperación. Los beneficios ecológicos del turismo industrial son evidentes, así como desde lo que se conoce como economía sostenible.

La red, en lugar de englobar a todas las regiones de industrialización tradicional de Europa, agrupará a los lugares más significativos. Arrancando de Gran Bretaña, cuna de la Revolución Industrial, con sitios como Ironbridge, Manchester, el valle del Derwent o Gales, la ruta llegaría luego al continente a través de Holanda, Bélgica, Luxemburgo, Norte de Francia (Pas de Calais, Lorena y Alsacia), Norte de España (País Vasco y Cataluña), Suiza y Norte de Italia (Piamonte, Lombardía y Véneto). Desde aquí se dirigiría a Austria, República Checa (Moravia), Polonia (Silesia), Finlandia (Häme), Suecia (Bergslagen) y Dinamarca (área metropolitana de Copenhague), para adentrarse posteriormente en Alemania (Renania del NorteWestfalia, Sarre y Ruhr). Estas tres últimas regiones son consideradas en la ruta como el corazón histórico de la industrialización europea.

\section{BIBLIOGRAFÍA}

AA.VV. (2004): Rutas culturales y turísticas del patrimonio industrial, Gijón, INCUNA.

Aguilar Civera, I. (1998): Arquitectura industrial. Concepto, método y fuentes, Valencia, Diputación de Valencia.

- (2003): «Patrimonio industrial. Aprovechamiento cultural y reutilización», en: Estructuras y paisajes industriales. Proyectos socioculturales y turismo industrial, Gijón, INCUNA, p. 41-61.

ALONSO IBÁNEZZ, M. R. (1999): «Patrimonio industrial. Notas a su insatisfactoria protección jurídica", Patrimonio Cultural y Derecho, 3, p. 257 y ss.

- (2002): "Aspectos normativos del patrimonio industrial», en: Patrimonio industrial: lugares de la memoria, Gijón, INCUNA, p. 109-127.

Álvarez Areces, M. A. (1992): "Recuperación y uso del patrimonio industrial», Ábaco. Revista de Ciencias Sociales, 1, p. 57-66.

- (2001): "Patrimonio industrial, identidad cultural y sostenibilidad", en: Arqueologia industrial, patrimonio y turismo cultural, Gijón, INCUNA, p. 13-32.

- (2003): «Industrias culturales y patrimonio industrial», en: Estructuras y paisajes industriales. Proyectos socioculturales y turismo industrial, Gijón, INCUNA, p. 15-40.

BENITO DEL POZO, P. (2002): "Patrimonio industrial y cultura del territorio", Boletín de la AGE, 34, p. 213227.

BERGERON, L. (2003): "La valorización turistica del patrimonio industrial", en: Estructuras y paisajes industriales. Proyectos socioculturales y turismo industrial, Gijón, INCUNA, p. 9-13.

CAPEL, H. (1996): “El turismo industrial y el patrimonio histórico de la electricidad", Actas de las I Jornadas sobre Catalogación del Patrimonio Histórico, Sevilla, Instituto Andaluz del Patrimonio Histórico, p. 170-195.

Casanelles Rahola, E. (1998): «Recuperación y uso del patrimonio industrial», Ábaco. Revista de Ciencias Sociales, 19, p. 11-18 
- (2002): «El patrimonio industrial en el contexto internacional», en: Gestión del Patrimonio Industrial en la Europa del s. XXI, Bilbao, Congreso Vasco de Patrimonio Industrial, p. 308-315.

COLLINET, H. D. (2002): “Emscher Park: zonas industriales. Desarrollo urbano y patrimonio industrial», en: Gestión del Patrimonio Industrial en la Europa del s. xxl, Bilbao, Congreso Vasco de Patrimonio Industrial, p. 58-73.

FELIÚ TORRAS, A. (1998): “El patrimonio industrial, localizaciones, regeneraciones: una nueva geografía", Ábaco. Revista de Ciencias Sociales, 19, p. 71-80.

GÓmez PRIETO, J. (2002): “Patrimonio industrial y turismo industrial", en: Gestión del Patrimonio Industrial en la Europa del s. XXI, Bilbao, Congreso Vasco de Patrimonio Industrial, p. 215-221.

LANDABASO, M. y otros (1989): Regiones europeas de antigua industrialización, Bilbao, SPRI Publicaciones.

LIURDÉs I COIT, J. C. (1999): «Patrimonio industrial y Patrimonio de la Humanidad. El ejemplo de las coIonias textiles catalanas. Potencialidades turísticas y algunas reflexiones", Boletín de la A.G.E, 28, p. 147-160.

LOPES CORDEIRO, J. M. (2001): “Museología y museografia industrial”, en: Arqueología Industrial, Patrimonio y Turismo Cultural, Gijón, INCUNA, p. 41-52.

Magán Perales, J. M. (2002): "La difícil definición y la escasa protección legislativa del patrimonio industrial. La situación legislativa estatal y autonómica», en: Gestión del Patrimonio Industrial en la Europa del s. XXi, Bilbao, Congreso Vasco de Patrimonio Industrial, p. 205-209.

NEVELL, M. (2002): "Regeneración y nuevos usos de las estructuras arqueológicas industriales en el Área de Manchester", en: Gestión del Patrimonio Industrial en la Europa del s. xxI, Bilbao, Congreso Vasco de Patrimonio Industrial, p. 36-57.

PARDO ABAD, C. J. (1997): “Caña, azúcar y máquinas de vapor: industrialización y patrimonio histórico industrial en la costa granadina», Studia Academica, 3, p. 55-76.

- (1998): "Las colonias industriales del alto Llobregat en la provincia de Barcelona", Studia Academica, 6, p. 9-48.

- (2004): "La reutilización del patrimonio industrial como recurso turístico. Aproximación geográfica al turismo industrial», Treballs de la Societat Catalana de Geografia, 57, p. 7-32.

- (2004): "Turismo industrial, patrimonio cultural y territorios de la industria", Actas del IX Coloquio de Geografía del Turismo, Ocio y Recreación, Zaragoza, $15 \mathrm{p}$.

- (2004): “Las ciudades británicas y la rehabilitación turística y residencial del patrimonio industrial», ACtas de las VI Jornadas Internacionales sobre Patrimonio Industrial, Gijón, $15 \mathrm{p}$.

Roux, E. (2000): Patrimoine industriel, Paris, Éditions Scala.

Sobrino SimAL, J. (1998): “La arquitectura industrial: de sala de máquinas a caja de sorpresas", Ábaco. Revista de Ciencias Sociales, 19, p. 19-28.

StRATTON, M. (2000): Industrial buildings, Londres, E. \& FN. Spon.

TAtjer, M. y VILANOVA, A. (2002): La ciutat de les fàbriques. Itineraris industrials de Sant Martí, Barcelona, Institut de Cultura.

Vall I CASAS, P. (1999): De colónies textils a Parc Fluvial. El sistema de Colònies Textils del Baix Berguedà, Barcelona, Marcombo / Associació d’Enginyers Industrials de Catalunya. 